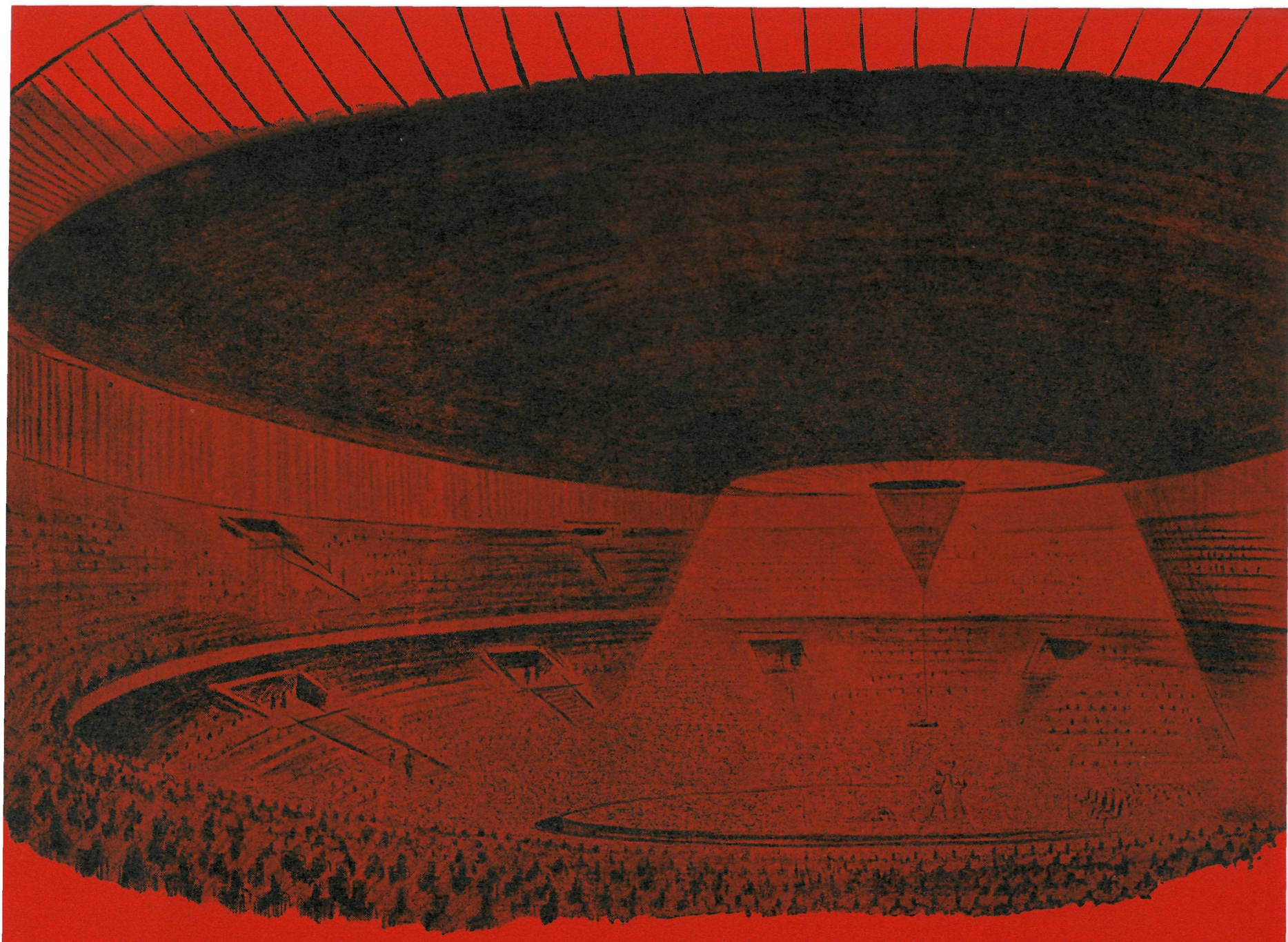

$839 \cdot 10$

\title{
cubierta en bóveda invertida
}

Infornnación amablemente facilitada por la Empresa Constructora Mondino y Viera de Mrontevideo.

SI N $\mathrm{N} \& \operatorname{IS}$

Ti ediffeio, inaugurado para una exposiciôn, está destinado a estadio deportivo, en da cludad de. Montevideo (Uruguay). Su originalidad radica en la cubierta, cuya estruetura está constituía nop dos anillos circulares, concéntrieos, entre los cuales se han montsdo 256 cables radiales que airven de soporte a las placas prefabricadas de cierre, formando una bóveda invertida. 

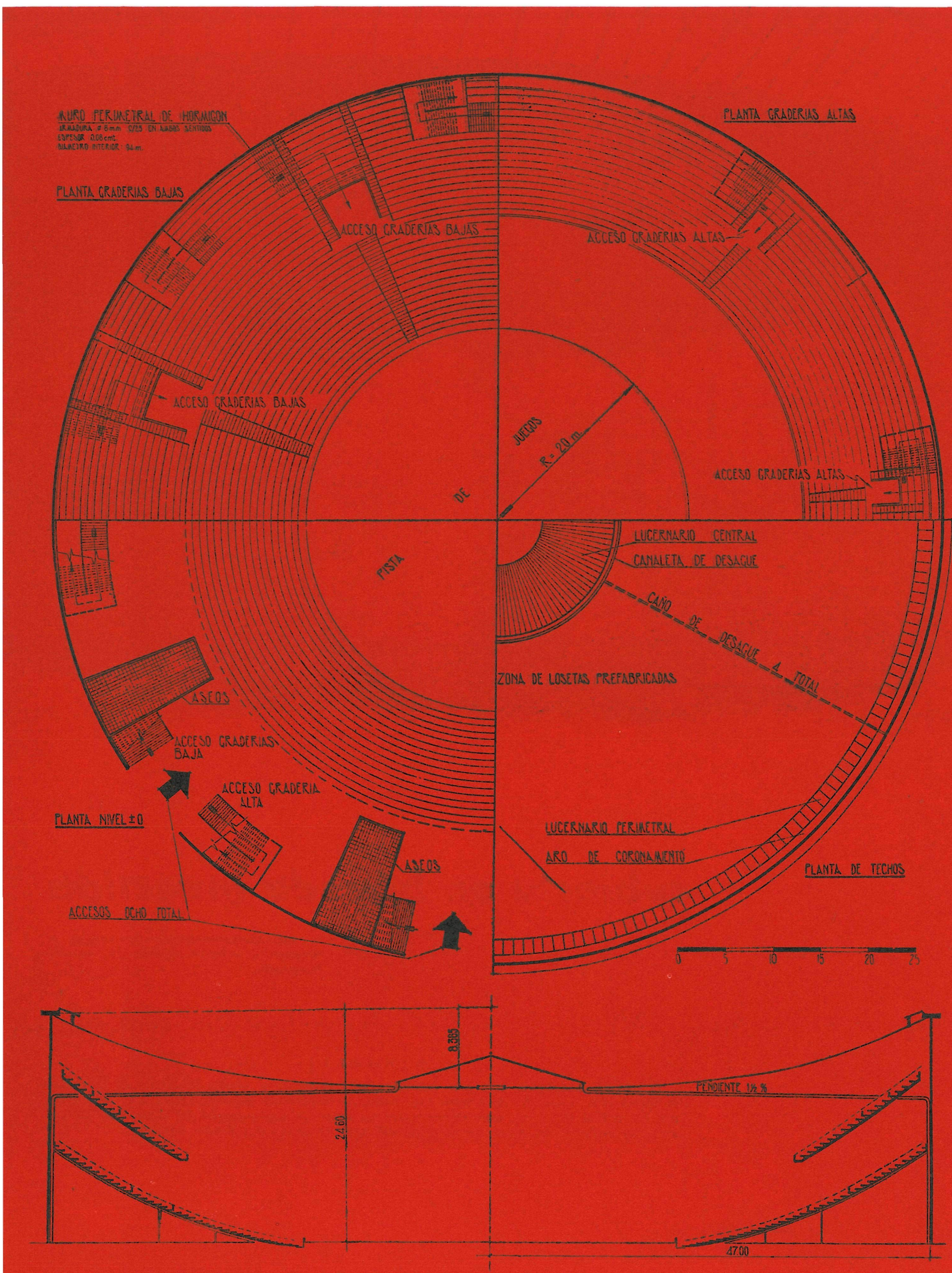

\section{planta y sección}




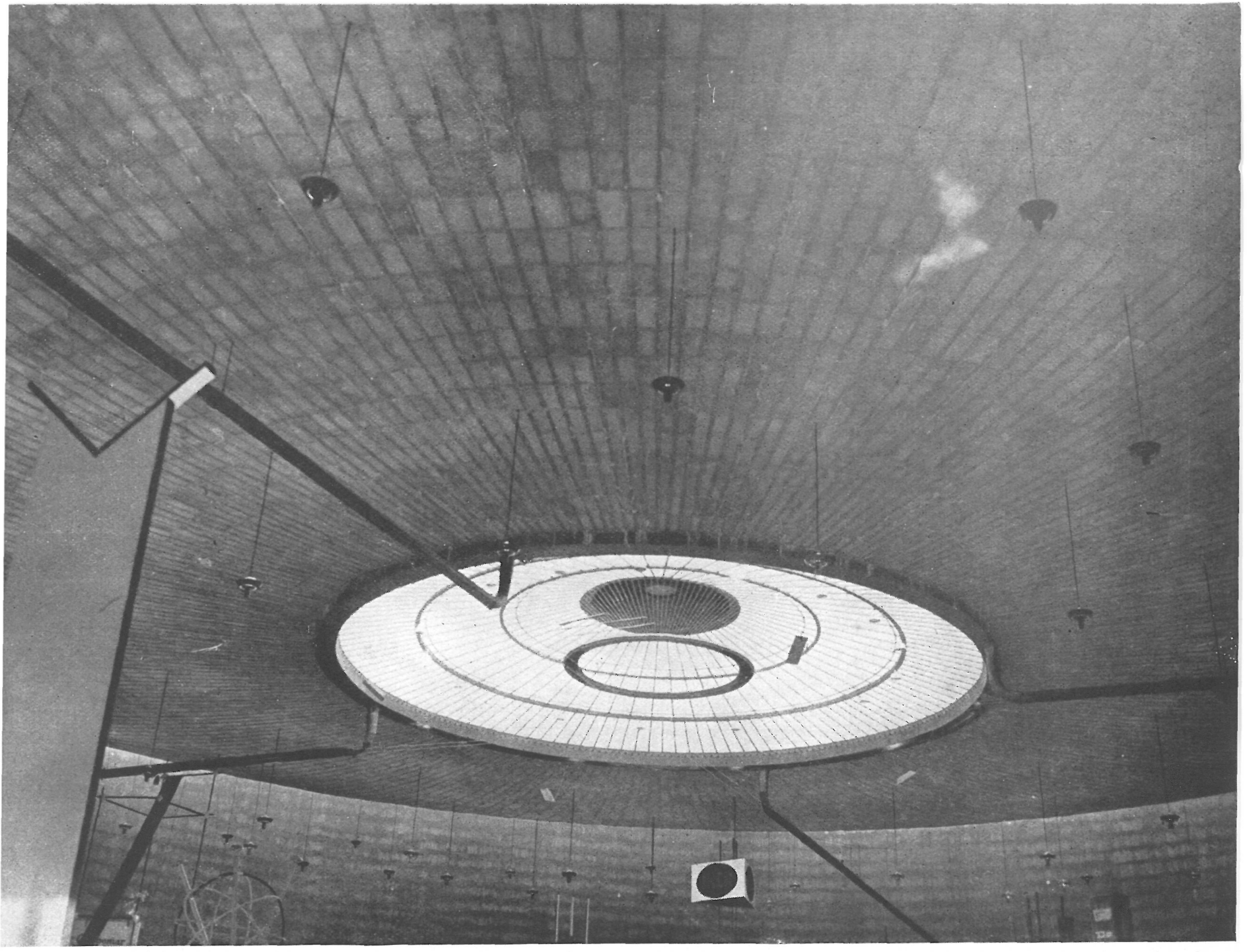

perspectivas

generalidades

Para la construcción de un edificio, que debía utilizarse en una primera fase como local de la Exposición Nacional de la Producción de Montevideo (Uruguay) y, posteriormente, como estadio cubierto para deportes, con una capacidad de 20.000 espectadores sentados, se abrió un concurso, para su proyecto y construcción, en el que sólo se exigía como condición que no existiesen soportes intermedios en la solución. Se presentaron tres tipos distintos de estructuras: uno de ellos consistió en una bóveda laminar de hormigón; otra que utilizaba el alu-

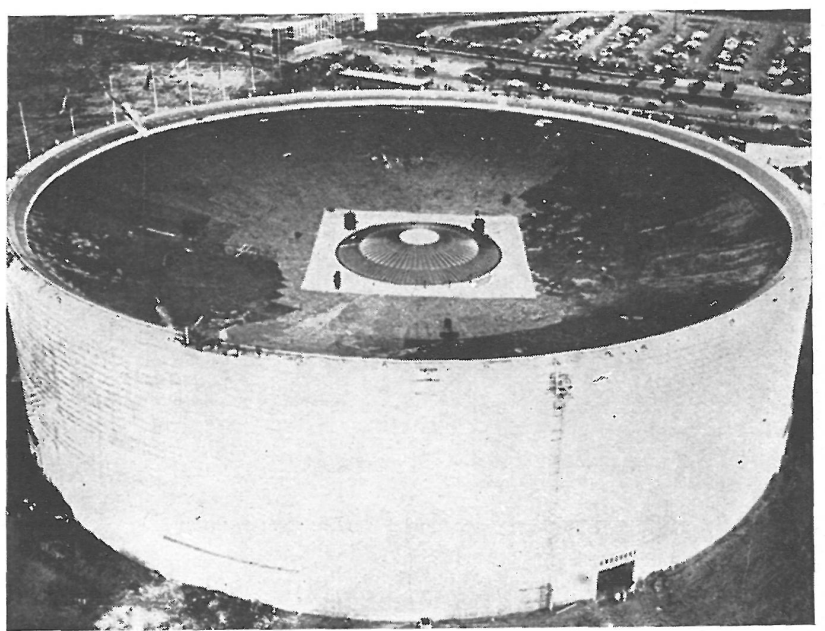




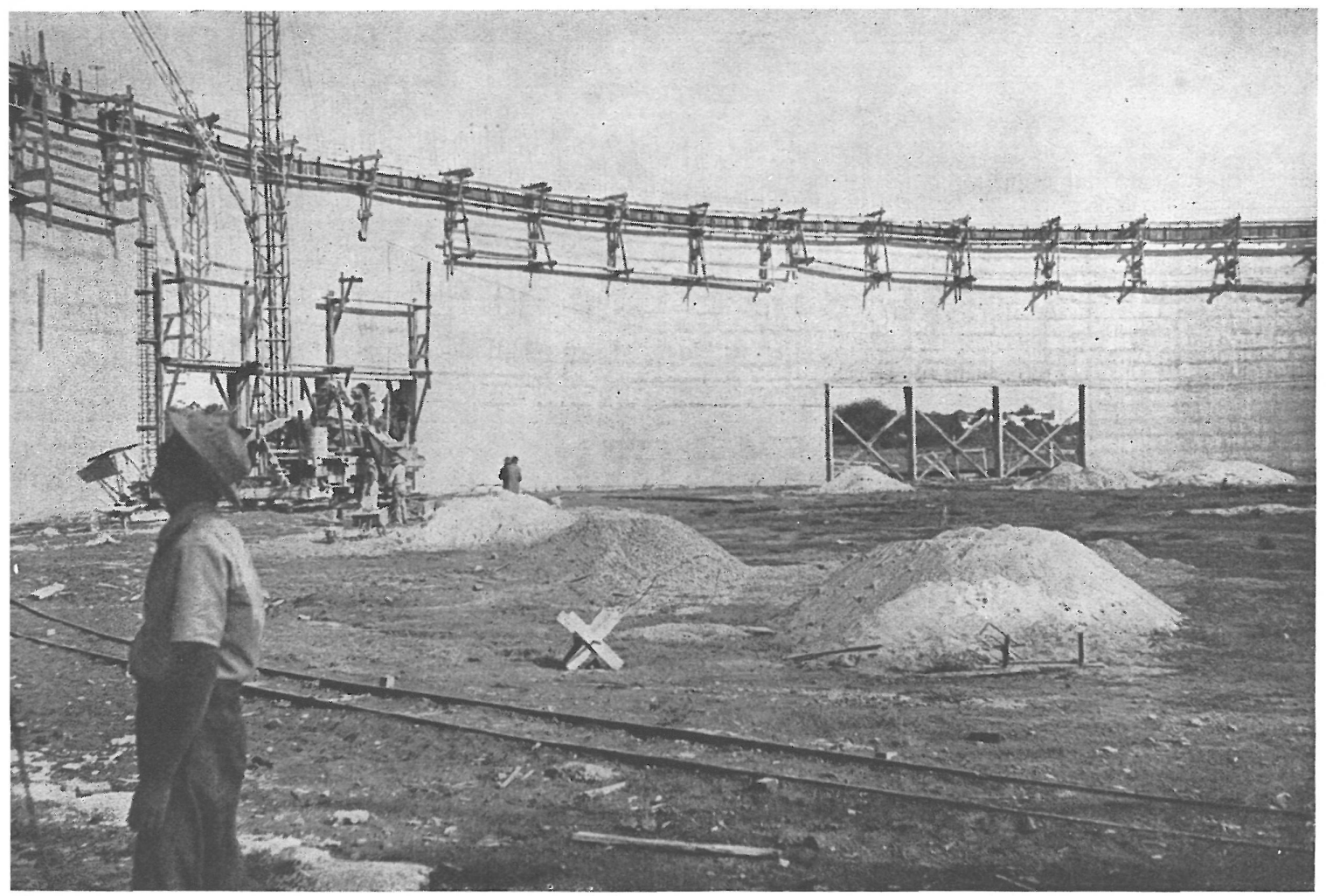

Para el hormigonado de los muros exteriores se empleó una torre sobre carriles.

minio, y, finalmente, una de tipo cilíndrico cubierta con una bóveda invertida. Esta última solución, que ha sido la adoptada, resultó ser cuatro veces más económica que la bóveda de hormigón. El plazo conferido para la ejecución era de catorce meses.

La solución elegida se caracteriza por dos curiosas modalidades: una de éstas consiste en la inversión de la bóveda, y la otra, por suspenderla por medio de un entramado de cables, sobre los que se apoyan los materiales de cubrición, que, en este caso, son placas prefabricadas de hormigón armado, de $5 \mathrm{~cm}$ de espesor, de forma trapezoidal, de $1 \mathrm{~m}$ de altura 0 distancia entre bases. apoyos o muros exteriores

E1 edificio tiene una planta circular de $94 \mathrm{~m}$ de diámetro, y para darle mayor capacidad de sustentación se fundó sobre pilotes. Los muros exteriores, de hormigón armado, son los soportes directos de la bóveda: su espesor es de $10 \mathrm{~cm}$ y su altura $25 \mathrm{~m}$. Para su construcción se han utilizado encofrados deslizantes formando un anillo de $0,70 \mathrm{~m}$ de altura, que cada día se iba subiendo. Estos encofrados van provistos de las plataformas de trabajo necesarias para el personal que hormigona, ayudándose para ello de una torre móvil, sobre carriles, que corre paralelamente al muro en la parte interior de la construcción.
1 Pie de la torre de hormigonado

2 Armaduras del anillo perimetral

3 Canaleta para transporte del hormigón

4 Una fase del hormigonado del anillo perimetral

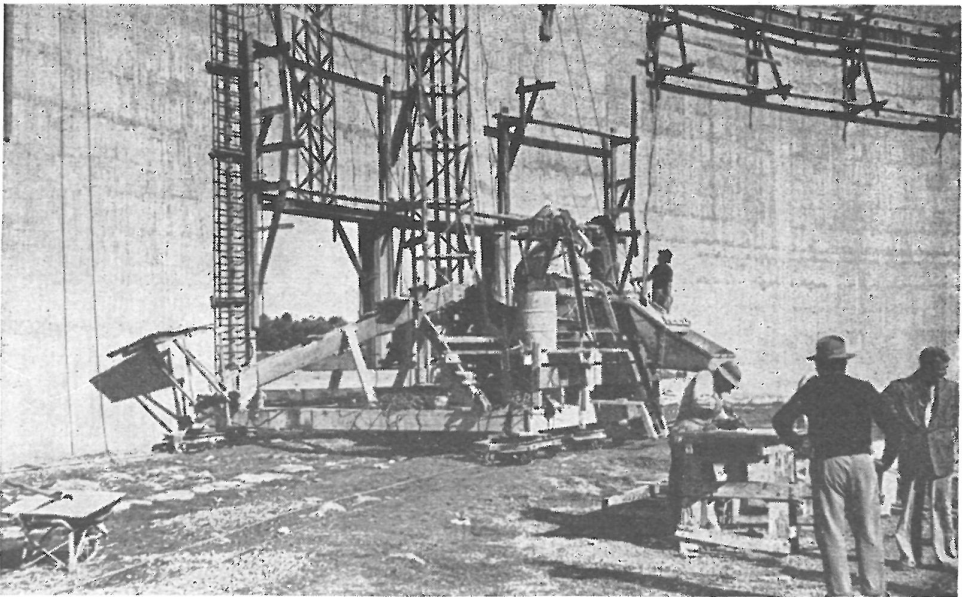

1 
Con objeto de permitir el avance diario antes indicado el cemento empleado es rápido y de $395 \mathrm{~kg} / \mathrm{cm}^{2}$ de resistencia a los catorce días.

\section{cúpula invertida}

$\mathrm{Su}$ diámetro es de $94 \mathrm{~m}$, la flecha de $8 \mathrm{~m}$ y su parte más baja se halla a $17 \mathrm{~m}$ del suelo. La armadura de la bóveda está formada por 256 cables radiales de $15 \mathrm{~mm}$ de diámetro cada uno de los cuales está constituído por siete alambres de $5 \mathrm{~mm}$. Las extremisiete alambres de $5 \mathrm{~mm}$. Las extremi-
dades de cada cable van provistas de una varilla fileteada para su anclaje por medio de tuercas.

Los cables se anclan en dos anillos concéntricos, uno metálico interior, suspendido por dos cables, de 5,70 m de diámetro, formado por dos chapas de $5 \mathrm{~cm}$ de espesor y $30 \mathrm{~cm}$ de anchura; y el otro, periférico, de hormigón $\mathrm{ra}$; y el otro, periférico, de hormigón
armado, de $0,45 \mathrm{~m}$ de altura y $2 \mathrm{~m}$ de anchura, que se apoya directamente sobre la coronación del muro de contorno.

La construcción de la cúpula invertida empezó montando el anillo interior sobre un castillete que servía de apoyo provisional, cuya altura fué de $16 \mathrm{~m}$. Así sostenido este anillo, se $16 \mathrm{~m}$. Así sostenido este anillo, se la armadura entre dichos anillos. Terminada esta operación se construyó un tercer anillo de hormigón, de $20 \mathrm{~m}$ de diámetro interior que sirve de apoyo del analón que ha de recoger las aguas de lluvia, cuyo desagüe se realiza por medio de cuatro bajantes con pendiente $1,5 \%$ que se dirigen a los muros, donde descienden segun la vertical.

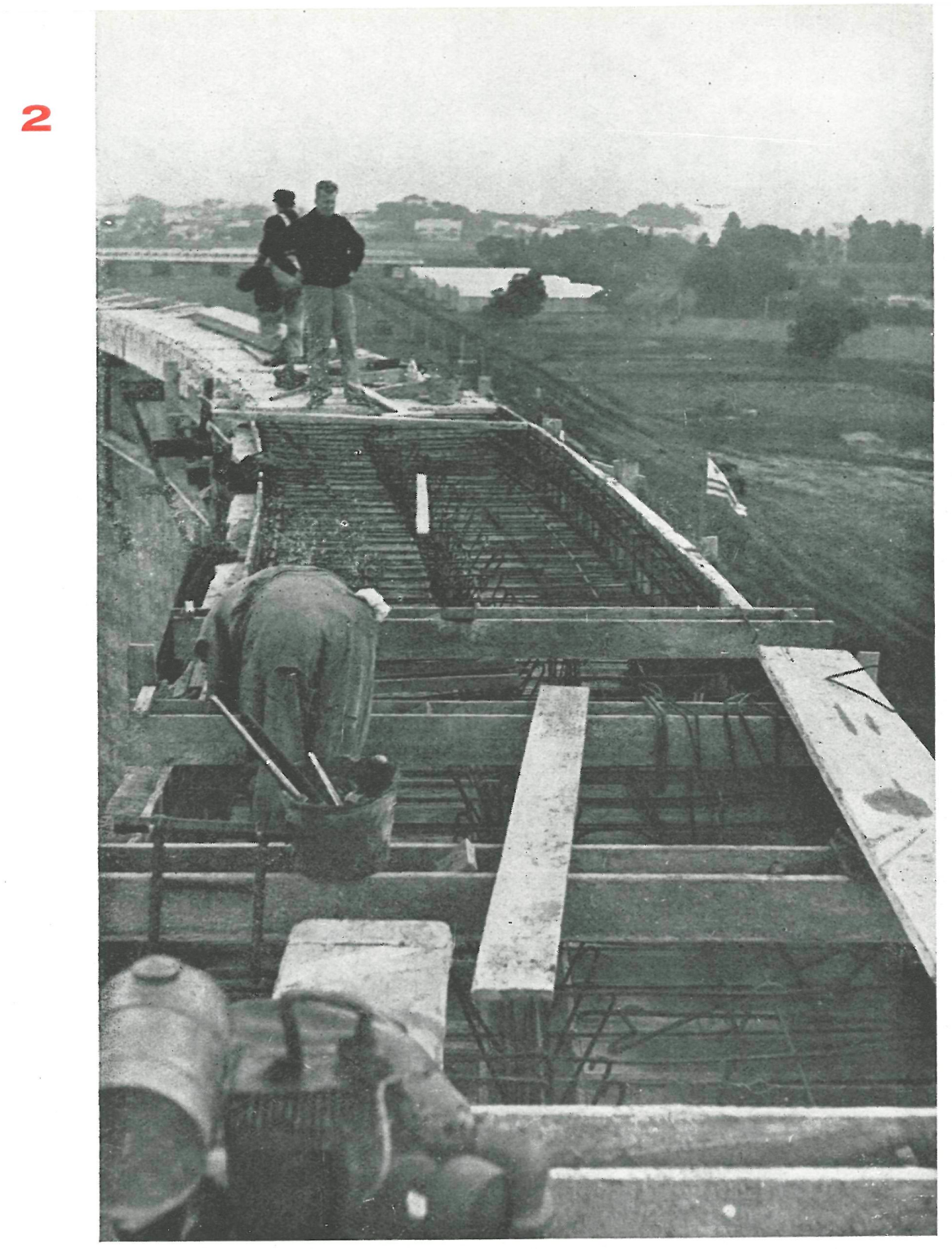

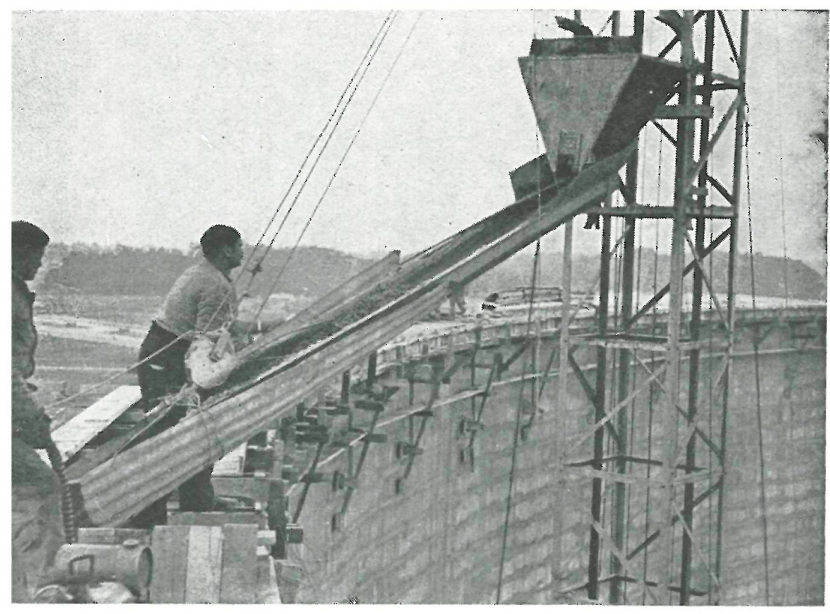

3

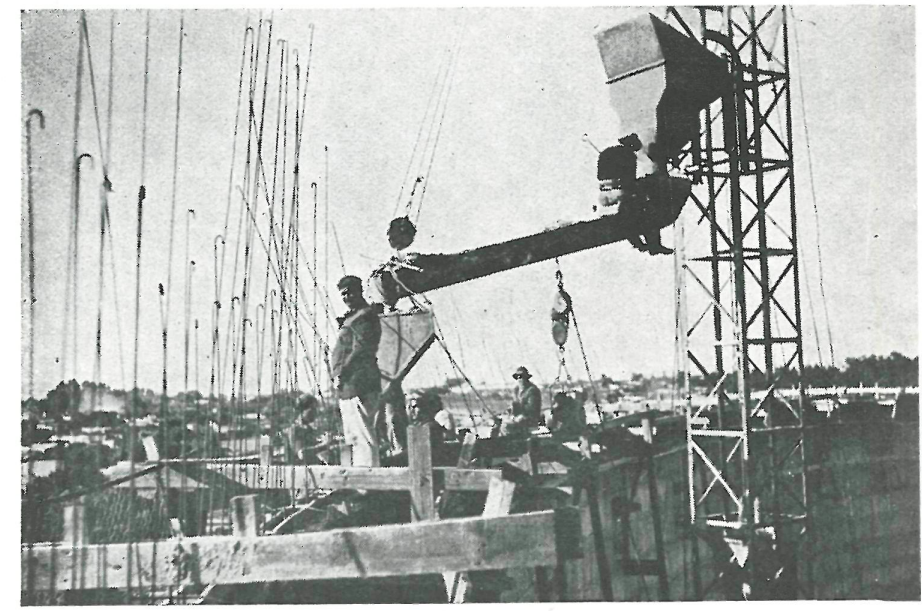

4 


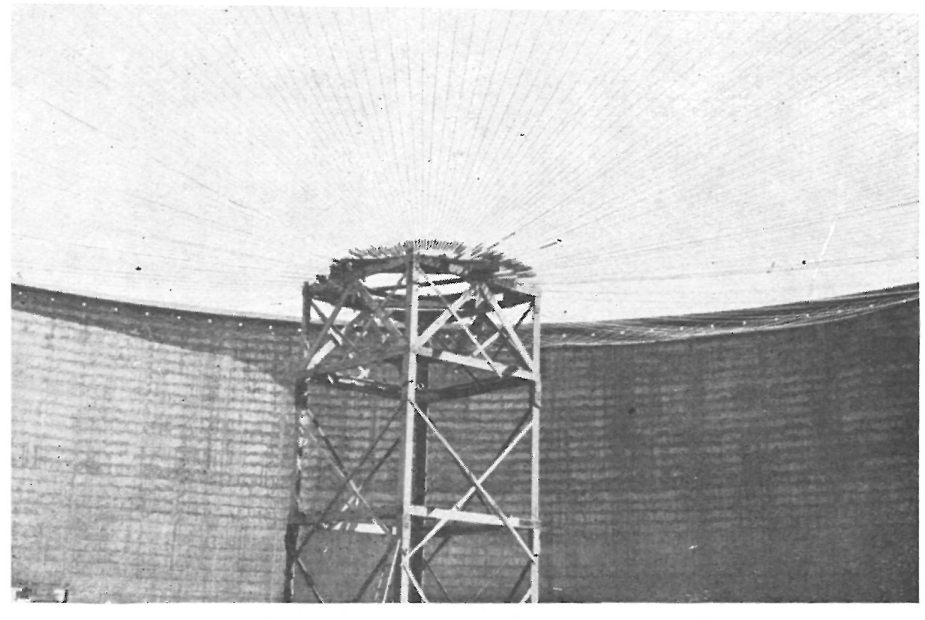

Este anillo de hormigón, atravesado por los cables de la armadura por medio de tubos galvanizados con objeto de independizarle de las variaciones de tensión que puedan experimentar los cables, sirvió también de apoyo de las primeras losetas de cubrición, de las que se utilizaron 900 para cubrir la bóveda.

\section{pretensado de la bóveda}

Una vez colocadas las losetas de cubrición sobre los cables, se procedió a repartir una sobrecarga inicial, equi-

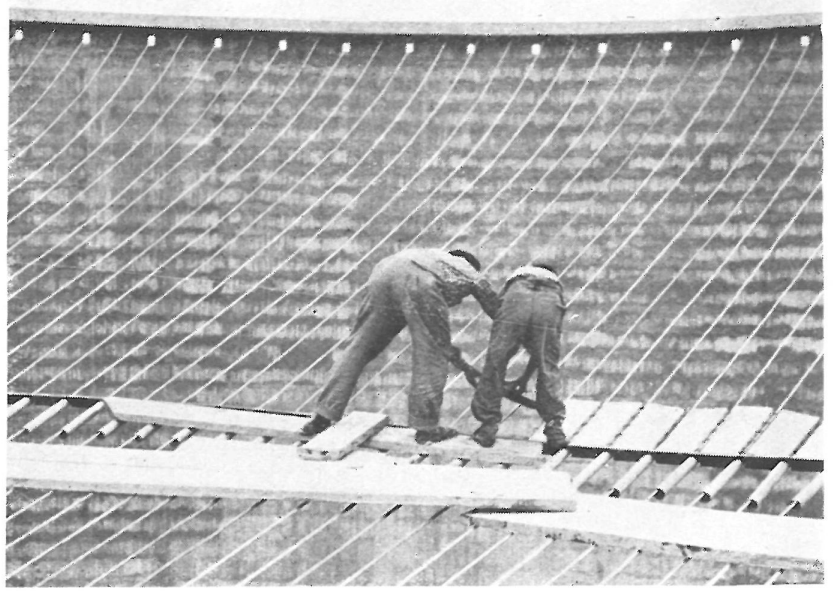

valente al $50 \%$ del peso propio de la cubierta, para cuya operación se emplearon ladrillos. Esta sobrecarga dio lugar a un tesado particular de las armaduras, después de lo cual se hizo el rejuntado, empezando por colocar cubrejuntas de fibrocemento, de $10 \mathrm{~cm}$ de anchura, en la parte inferior de la bóveda, rellenando las juntas por la parte superior con mortero de cemento. Terminado el rejuntado y fraguado el mortero, se retiraron los ladrillos utilizados para la sobrecarga de tesado, queclando la bóveda finalmente pretensada.

Anillo metálico central soportado con un castillete.

Preparando el apoyo y colocación de las losetas.

Repartición de la sobrecarga qu sirvió para el pretensado.

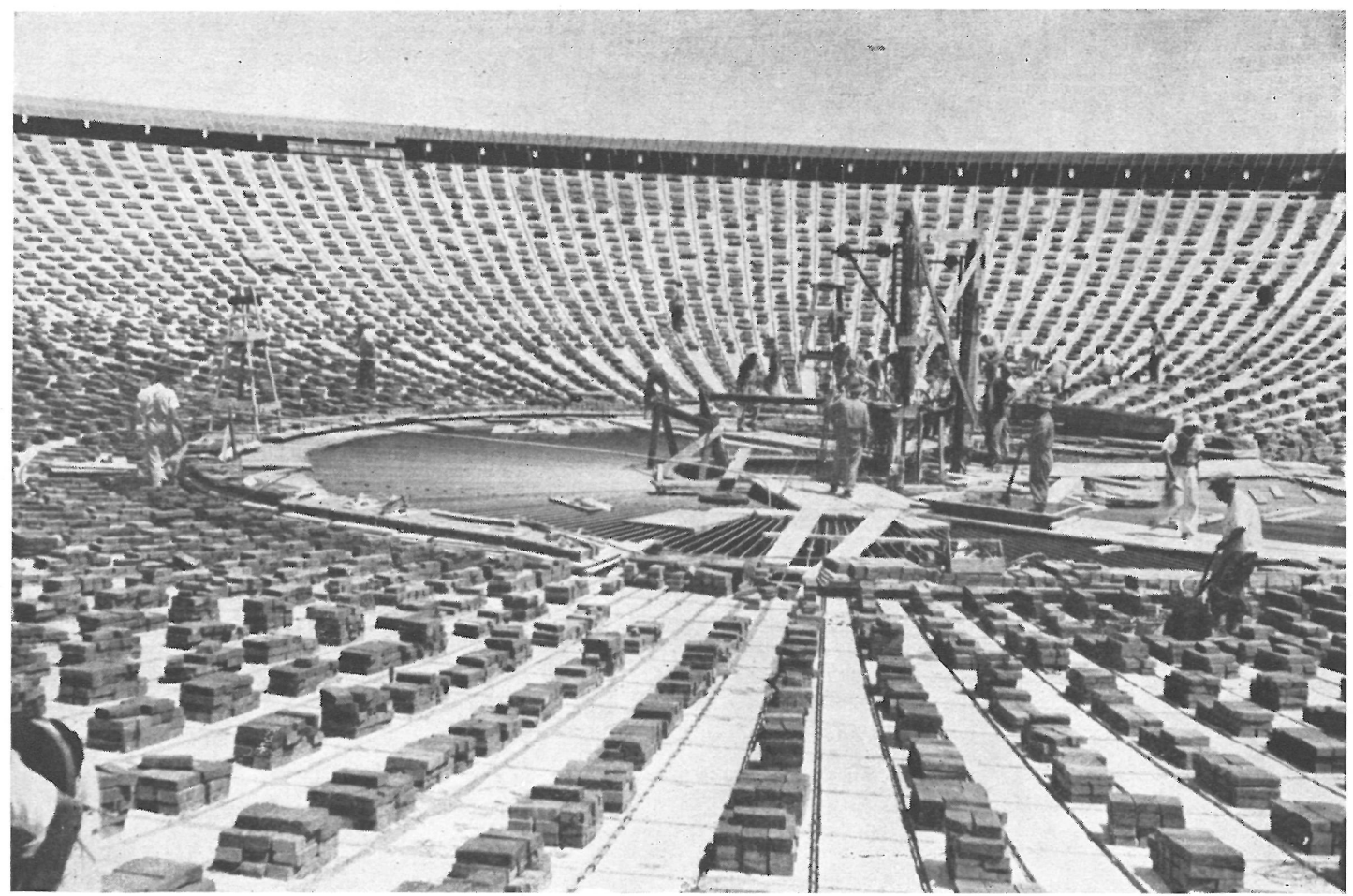



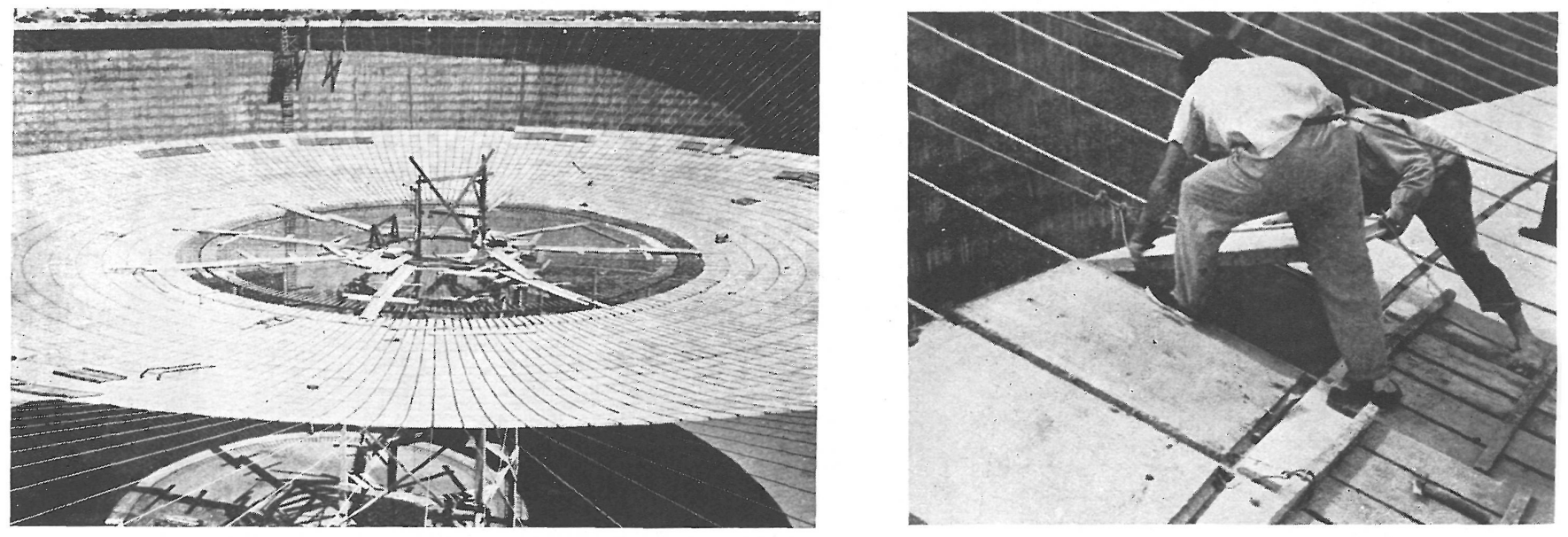

estabilidad de la cubierta

El cálculo que sirvió de base para el estudio de la estabilidad de la obra al someterla a la acción del viento utilizó las normas técnicas uruguayas, que, no obstante, y para mayor seguque, no obstante, y para mayor segu-
ridad, se hicieron una serie de ensayos aerodinámicos de comprobación.

Una fase avanzada de la colocación de

losetas.

La presión ejercida por el viento a una altura de 20 a $40 \mathrm{~m}$, según dichas normas, resultó ser de $130 \mathrm{~kg} / \mathrm{m}^{2}$. Estudiado el fenómeno convenientemente se llegó a las conclusiones siguientes:

1. En ningún caso existirán presiones de arriba hacia abajo en la cubierta.

2." Las depresiones más elevadas corresponden a la parte central de la cubierta.

3.: La depresión de mayor importancia será de $-80 \mathrm{~kg} / \mathrm{m}^{2}$ y $61 \mathrm{~kg} / \mathrm{m}^{2}$ para la presión.

Como el peso total de la cubierta es del orden de $125 \mathrm{~kg} / \mathrm{m}^{2}$, no cabe la posibilidad de que se levante, ni correr grave riesgo por la sobrecarga de $61 \mathrm{~kg} / \mathrm{m}^{2}$, ya que la repartida para las operaciones de tesado de los cables de la armadura fué equivalente a ésta, aproximadamente.

\section{ventajas de este tipo de} estructuras

La bóveda invertida de este tipo no sólo presenta gran ventaja de la rapidez y bajo coste de construcción, sino que se comporta mejor, desde el punto de vista acústico, que las bóvedas ordinarias.

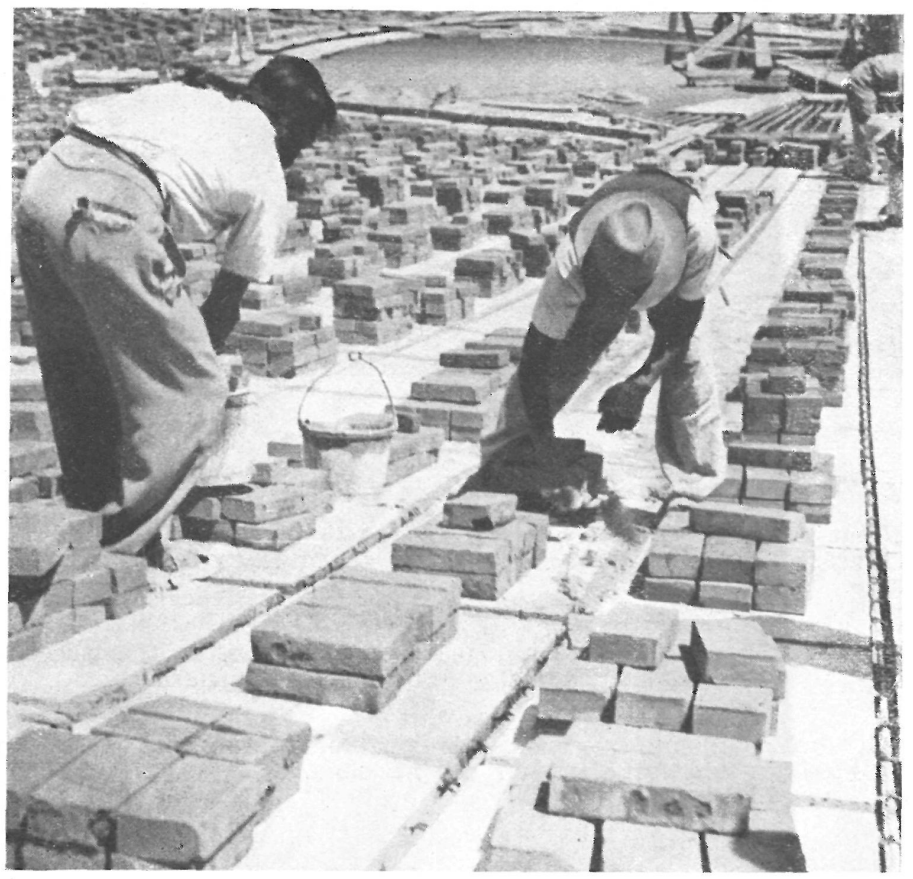




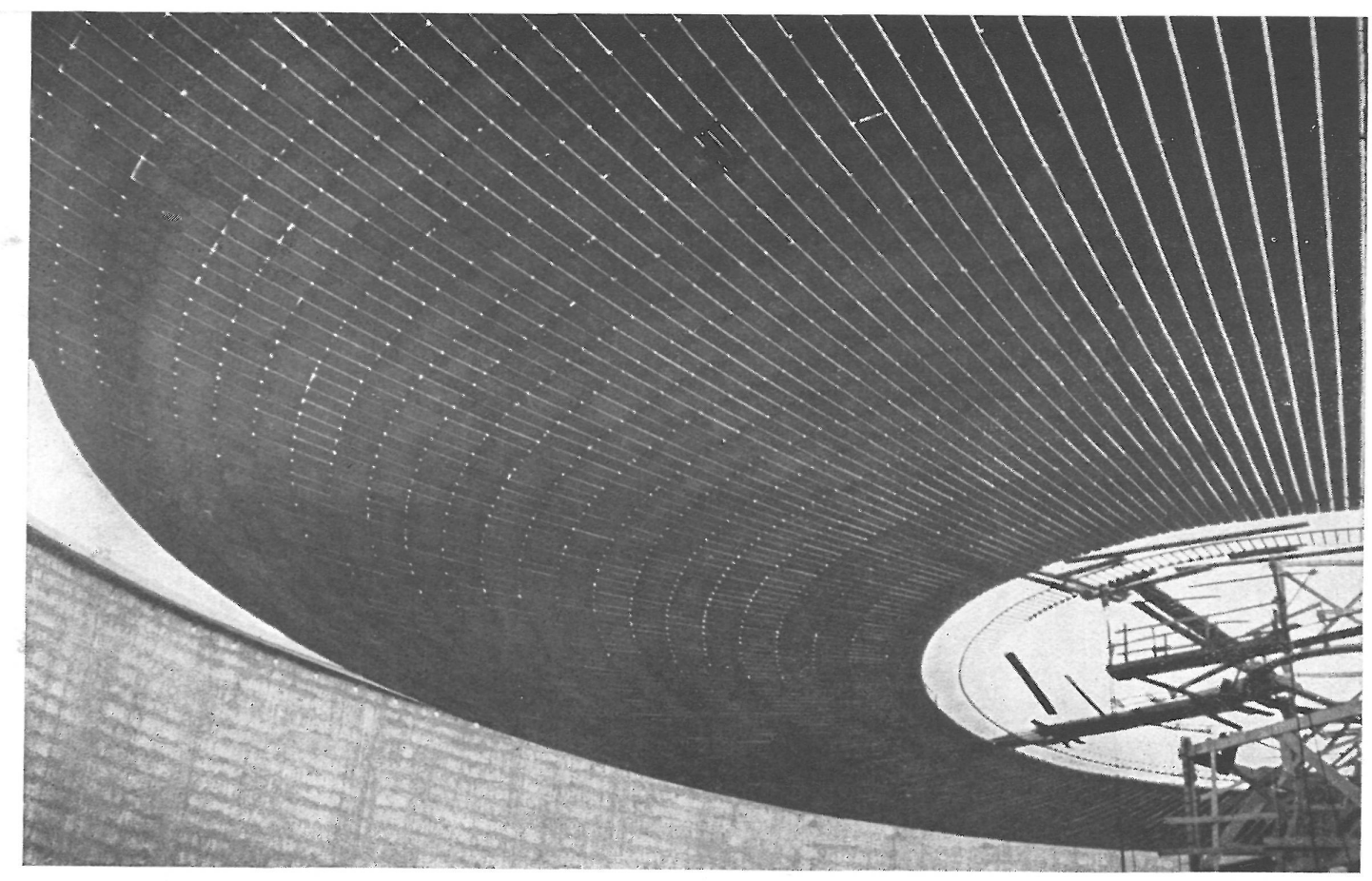

Aspecto interiot de la bóveda, aún no terminada.

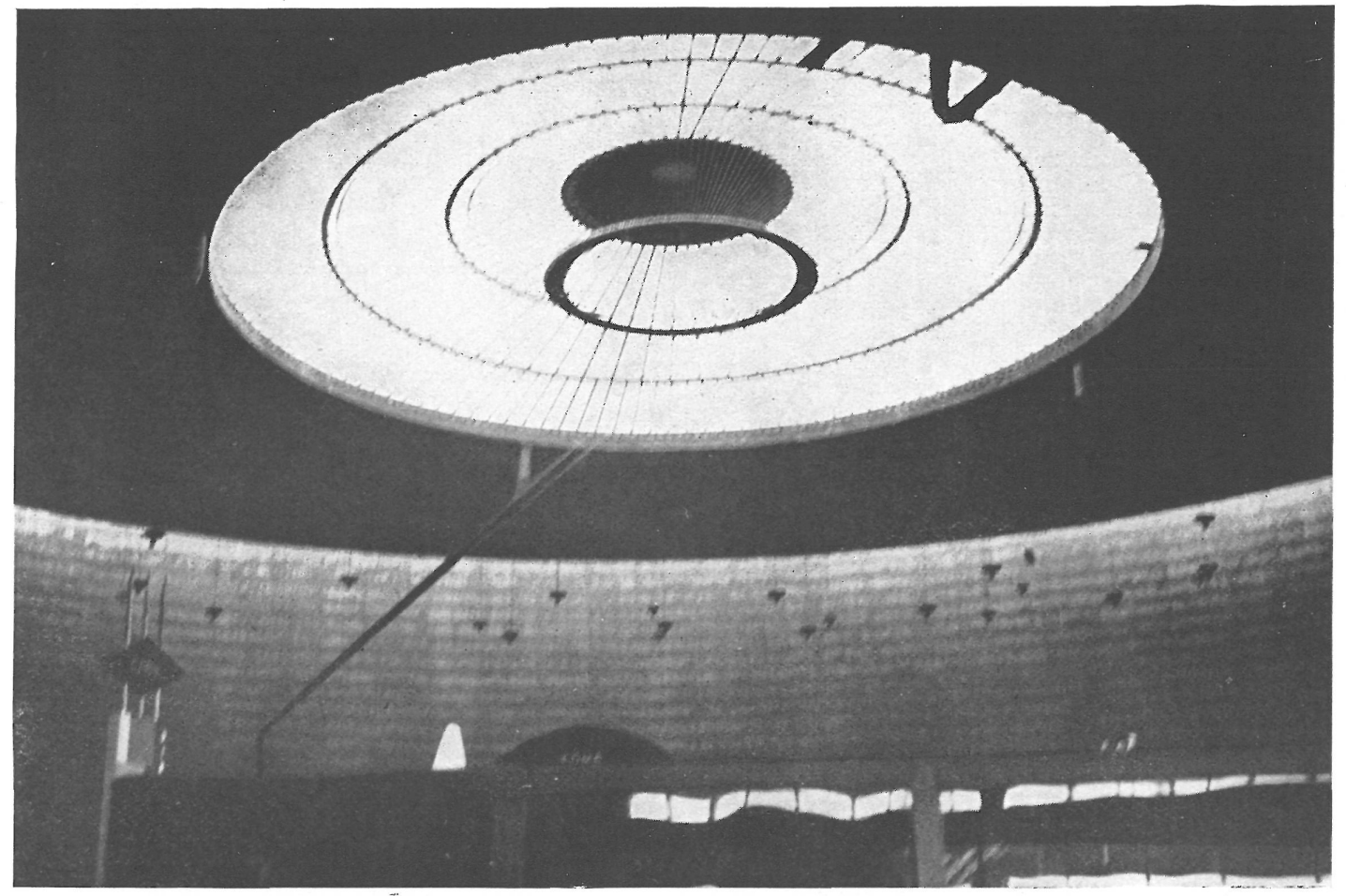

Vista interioz

Estas concentran los sonidos en su parte central, mientras que las invertidas la reflejan hacia las paredes laterales, donde, por tanto, se protegen con materiales absorbentes acústicamente hablando.

La esbeltez y ligereza que presentan estos tipos de construcciones tiene su origen en la forma favorable, estructuralmente, en que trabajan los materiales.

Este procedimiento de construcción, patentado en varios países, ha sido proyectado, en esta obra, por Mondino, Viller y Viera, en colaboración con el arquitecto Ríos y empresa constructora Mondino y Viera Ltd.

$$
\text { J. J.U. }
$$

